Original Research Paper

\title{
Traction Enhancing Products Affect Maximum Torque at the Shoe-Floor Interface: A Potential Increased Risk of ACL Injury
}

\author{
${ }^{1}$ Morse, A., ${ }^{2}$ M.M. Mansfield, ${ }^{1}$ R.M. Alley, ${ }^{3}$ H.A. Kerr and ${ }^{4}$ R.B. Bucinell \\ ${ }^{I}$ Albany Medical College, Orthopaedic Surgery, Albany, NY, USA \\ ${ }^{2}$ Binghamton University, Mechanical Engineering, Vestal, NY, USA \\ ${ }^{3}$ Albany Medical College, Internal Medicine/Pediatrics, Albany, NY, USA \\ ${ }^{4}$ Union College, Mechanical Engineering, Schenectady, NY, USA
}

Article history

Received: 22-08-2016

Revised: 27-09-2016

Accepted: 28-09-2016

Corresponding Author:

Mansfield M.

Binghamton University,

Mechanical Engineering, Vestal,

NY, USA

Email: mmansfi1@binghamton.edu

\begin{abstract}
The knee is one of the most frequently injured joints in the body, between 100000 and 400000 Anterior Cruciate Ligament (ACL) injuries occur in the United States each year. This investigation explores the impact of wipe- or spray-on sneaker products used to increase traction between shoes and hardwood courts on the loading of the ACL. Specifically, the maximum torque achieved prior to the sneaker slipping on the court surface is measured using a servo-hydraulic bi-axial load frame. A prosthetic foot fitted into a sneaker was fixed to the load cell and a piece of hardwood court was fixed to the actuator of the load frame. Axial loads were applied to simulate an athlete's body weight and torques were applied to simulate an athlete pivoting on a hardwood surface. The maximum torque achieved prior to the sneaker slipping on the hardwood surface was measured. The investigation finds that the application of the wipe- or spray-on sneaker products increases the maximum torque achieved prior to the sneaker slipping by $164 \%$. This increase in torque exceeds prior published levels of torque that resulted in ACL failure in a cadaveric model.
\end{abstract}

Keywords: Anterior Cruciate Ligament, Anti-Slip Products, Surface Traction, Ligament Torque

\section{Introduction}

The knee is one of the most frequently injured joints; Hootman et al. (2002) estimates the knee accounts for $19 \%-23 \%$ of all musculoskeletal injuries. Furthermore, ACL tears are one of the most costly sports injuries with 100000 ACL reconstruction surgeries performed in the United States per year (Racine, 2014) costing an estimated \$1 billion (CDCP, 2006).

Many professional and amateur athletes utilize wipe- or spray-on products on the bottom of their sneakers to increase traction while playing sports on a hardwood court to improve performance. The advertised benefits of traction enhancing products include decreased slipping, increased ability to stop short and the ability to change direction quickly. These maneuvers often result in compressive, valgus and rotational forces about the knee joint.

It has been shown that tibiofemoral compression combined with valgus rotation or internal rotation (Hewett et al., 2005) generates tensile stresses within the ACL, especially with the knee in full extension to 30 degrees of flexion (Griffin et al., 2000). There has been little discussion about increased stress on the ACL and potential for increased risk of injury to the ACL with application of an anti-slip sneaker product.

This study compares the maximum torque achieved prior to the slip point between a sneaker and a hardwood floor with and without the application of an anti-slip product. This data is compared to published values in order to predict if ACL rupture is more likely after application of an anti-slip shoe product.

\section{Materials and Methods}

An experimental study was conducted to directly measure the maximum torque applied to a sneaker prior to slipping on a hardwood floor. Preparation for this study required the development of a test method that would simulate the loading between a sneaker and a hardwood floor as a player pivots and the identification of the factors that could influence slip between these two surfaces. 


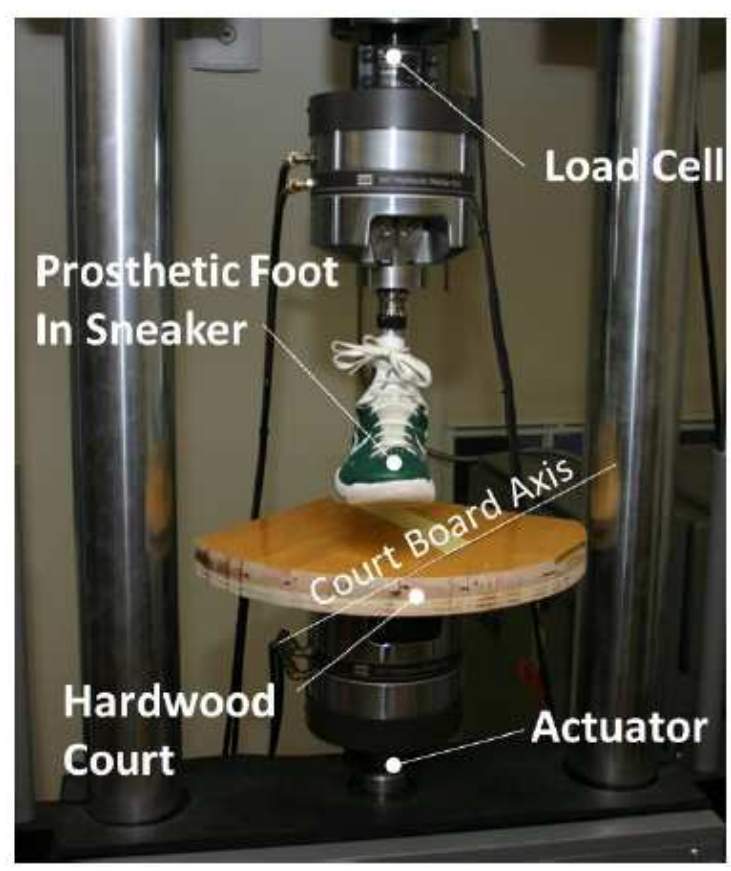

Fig. 1. Experimental set up of the sneaker and hardwood court installed in the bi-axial servo-hydraulic load frame. The board axis represents the direction of the court boards

\section{Experimental Set-up}

The main objective of the experimental set up was to accurately simulate the loading of a player pivoting on a hardwood floor. This type of loading includes the player's body weight (axial), inertial load (axial) and the torque generated by the pivoting motion. This bi-axial load profile motived the use of a servo-hydraulic bi-axial (axial-torsion) load frame. The experimental set up used in the investigation is shown in Fig. 1.

The experimental set-up includes a piece of hardwood court that was procured from a university basketball arena. The piece was trimmed to fit between the columns of the servo-hydraulic load frame and the seams between boards (Court Board Axis, Fig. 1) were carefully oriented so the shoe could be oriented in a range of positions from parallel to the seam to perpendicular to the seam and still be able to rotate a total of $20^{\circ}$. The hardwood court was anchored to a metal fixture using metal pins. The metal fixture was designed to fit into the hydraulic grip of the load frame.

A SACH (Solid Ankle Cushioned Heel) type prosthetic foot was attached to a fixture that was designed to fit into the hydraulic grip on the load frame. The prosthetic foot was inserted into a representative basketball sneaker manufactured by Nike (Beaverton, OR) as shown in Fig. 1. The fixture was designed so the entire plantar surface of the foot was in contact with the hardwood court.

"Court Grip" traction enhancer from Mission Athletecare (New York, NY) was the anti-slip product chosen for this study. This product was chosen because of its popularity and endorsement from the National Basketball Association (NBA) and the National Collegiate Athletic Association (NCAA).

\section{Design of Experiment}

The four parameters that this experimental set-up controlled included: the axial load applied to the sneaker (Load), the rate at which the sneaker was rotated (Rate), the orientation of the sneaker to the boards of the court surface (Orientation) and if anti-slip shoe product was applied to the shoe (Spray). The design of this experiment includes three levels of Load (445N (100lb), 667N (150lb) and $890 \mathrm{~N}(200 \mathrm{lb}))$, three levels of Rate $(1 \% \mathrm{~s}, 5 \% \mathrm{~s}$ and 10 $\%$ s), three levels of Orientation $\left(0^{\circ}\right.$ (Parallel), $45^{\circ}$ (Oblique) and $90^{\circ}$ (Perpendicular) to the Court Board Axis) and two levels of Spray (no-Spray and Spray). A full factorial design of experiments (Box et al., 2005) was employed with two replicates. Thus the total number of experiments performed:

$$
\begin{aligned}
& \text { Load Rate Orientation Spray Replicates } \\
& 3 \times 3 \times 3 \times 2 \times 2=108
\end{aligned}
$$

The experimental program was designed to first test all the no-Spray configurations (54 tests) and then test all the Spray configurations (54 tests). This insures that there is no spray contamination on the hardwood court surface during the no-Spray tests. The remaining test parameters (Load, Rate and Orientation) were randomized using a Latin Square strategy (Box et al., 2005) to minimize the impact of uncontrolled factors.

\section{Experimental Procedures}

Each of the 108 experimental trials followed the same experimental procedure. First the axial actuator of the load frame shown in Figure 1 was raised to apply the desired axial load as measured by the load frames load cell. The frame was then set to maintain this position throughout the test. Then under displacement control, the hardwood court was rotated at a designated rate up to $20^{\circ}$ of rotation and the torque generated by the sneaker sticking to the hardwood court was measured using the load frame's load cell. Axial load, axial displacement, torque and torsional displacement were electronically recorded at a sampling rate of 100 samples per second.

\section{Results}

For each of the 108 test conducted in this investigation, torque versus actuator rotation curves were generated. Figure 2, 3 and 4 show typical curves for the configuration where respectively a $445 \mathrm{~N}$ (100 lb) axial load, $670 \mathrm{~N}(150 \mathrm{lb})$ axial load and $890 \mathrm{~N}$ $(200 \mathrm{lb})$ axial load were applied to the sneaker during the rotation of the sneaker on the hardwood court. 


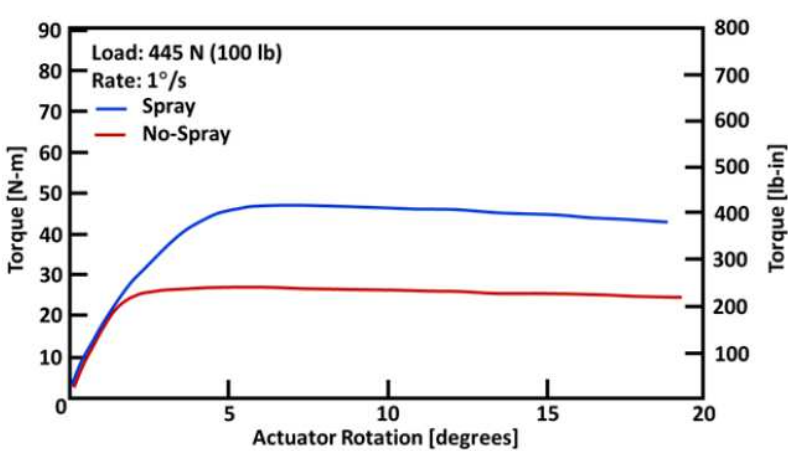

(a)

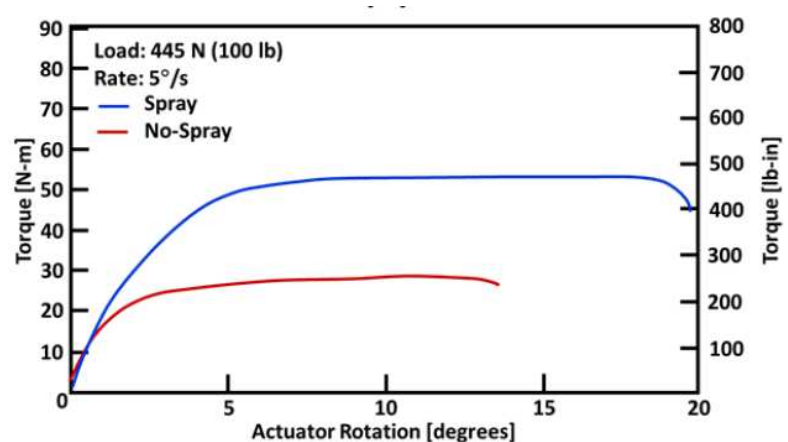

(b)

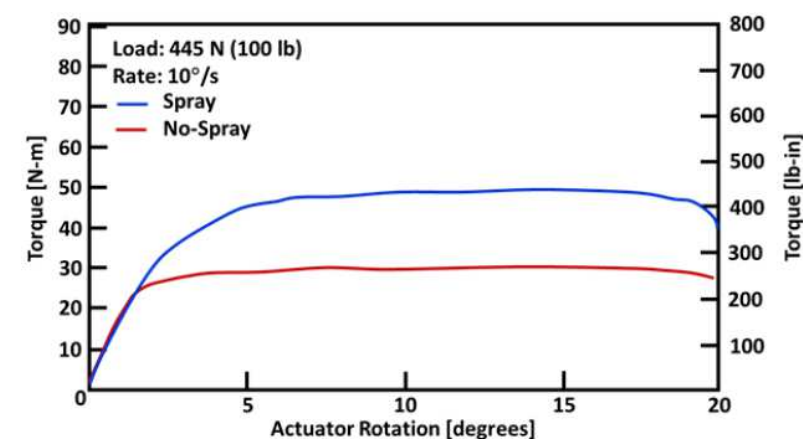

(c)

Fig. 2. Typical torque versus actuator rotation curves for $445 \mathrm{~N}$ of axial load. Both the spray and no-spray curves are shown for rotation Rates of (a) $1 \mathrm{deg} / \mathrm{s}$, (b) $5 \mathrm{deg} / \mathrm{s}$, and (c) $10 \mathrm{deg} / \mathrm{s}$

In each of these figures, curves for (a) $1 \%$ s, (b) $5 \%$ s and (c) $10 \%$ s. are shown. Each sub-figure includes the spray and no-spray results.

The experimental Torque versus Rotational Displacement curves were used to determine the maximum values of torque for each of the 54 combinations of Load, Rate, Orientation and Spray. This data was imported into the statistical software package JMP Pro by SAS Inc. First a regression analysis was performed on the data to determine which of the main effects (Load, Rate, Orientation, Spray) and corresponding higher order interactions were of significance.

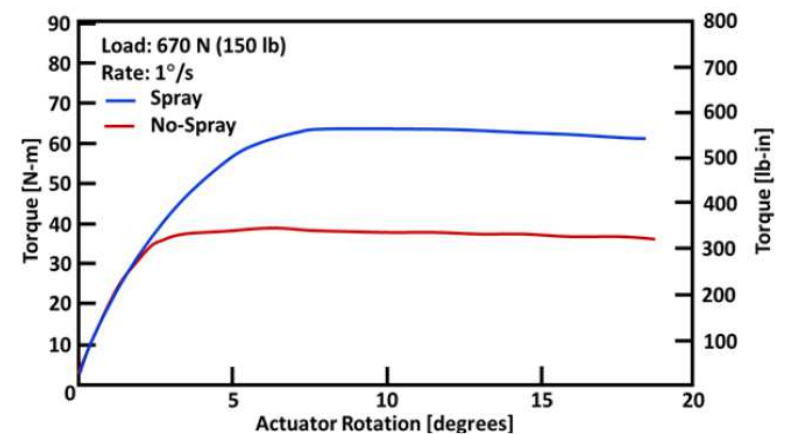

(a)

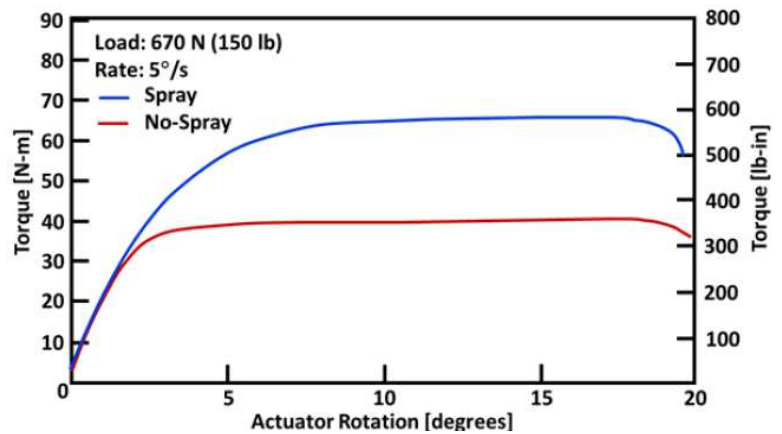

(b)

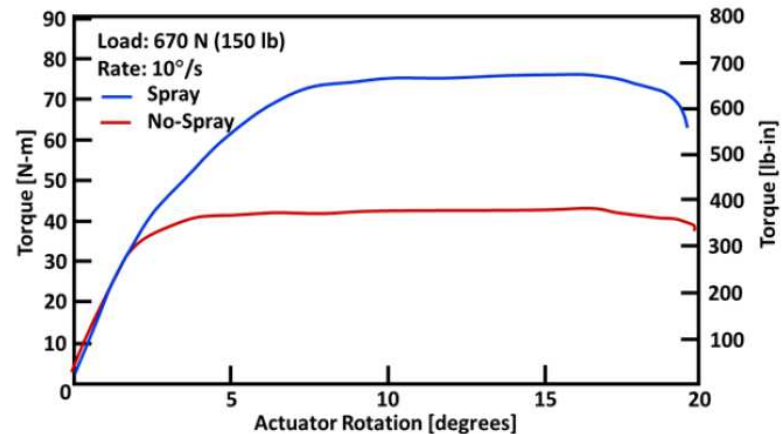

(c)

Fig. 3. Typical torque versus actuator rotation curves for $670 \mathrm{~N}$ of axial load. Both the spray and no-spray curves are shown for rotation Rates of (a) $1 \mathrm{deg} / \mathrm{s}$, (b) $5 \mathrm{deg} / \mathrm{s}$, and (c) $10 \mathrm{deg} / \mathrm{s}$

Table 1. P-values that resulted from the regression analysis performed on the maximum torque data for the four factors under consideration in this study. Only first order factor P-values are shown

\begin{tabular}{ll}
\hline Factor & P-value \\
\hline Load & $<0.0001$ \\
Rate & $<0.0001$ \\
Spray & $<0.0001$ \\
Orientation & 0.5000 \\
\hline
\end{tabular}

The data was first used to screen which of the factors had a significant effect on the maximum torque data. Table 1 shows the P-values for the main factors in this experiment (Load, Rate, Spray and Orientation). 


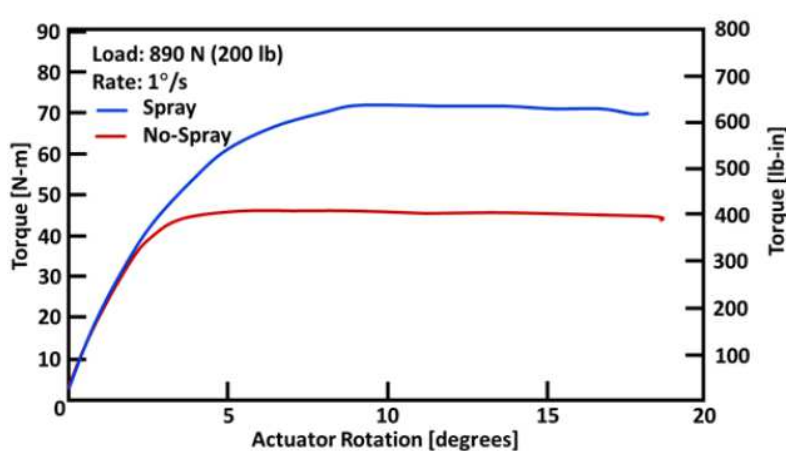

(a)

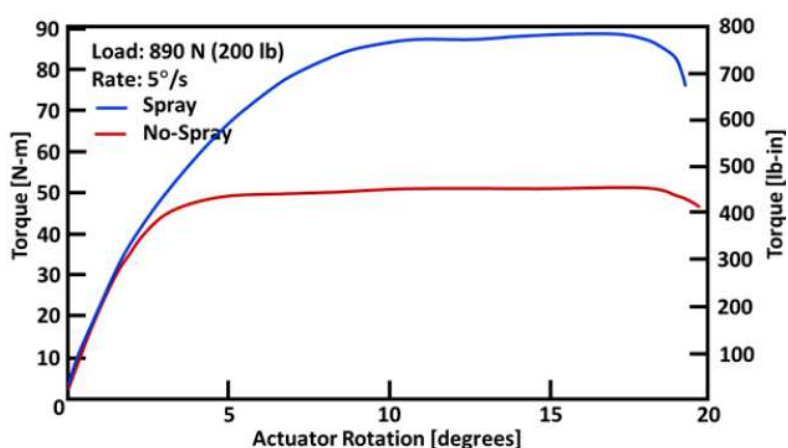

(b)

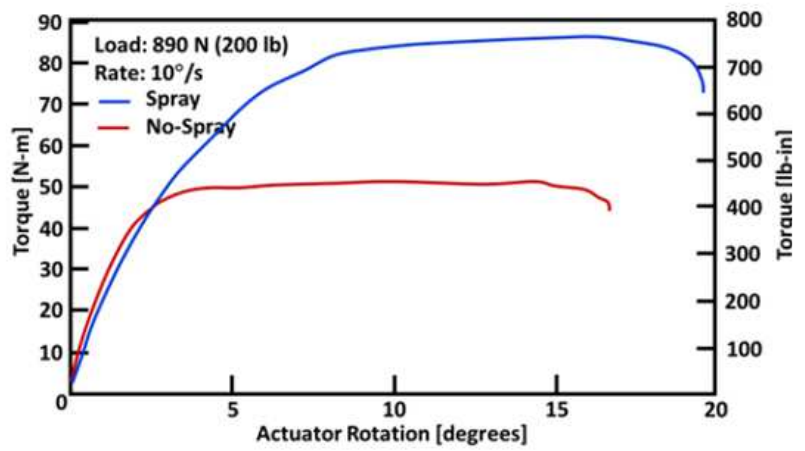

(c)

Fig. 4. Typical torque versus actuator rotation curves for 890 $\mathrm{N}$ of axial load. Both the spray and no-spray curves are shown for rotation Rates of (a) $1 \mathrm{deg} / \mathrm{s}$, (b) $5 \mathrm{deg} / \mathrm{s}$, and (c) $10 \mathrm{deg} / \mathrm{s}$

Of these four factors Load, Rate and Spray were found to be significant and Orientation was found not to be significant. The analysis performed also evaluated the significance of all the higher order interactions between the factors. None of the higher order interactions were found to be significant.

The three significant main factors in this study are further evaluated using Box-Whisker Plots. First the maximum torque data is plotted versus Rate of actuator rotation is shown in Fig. 5. Although the P-values shows the trend to be significant, the trend is very small and will not be considered further in this paper.

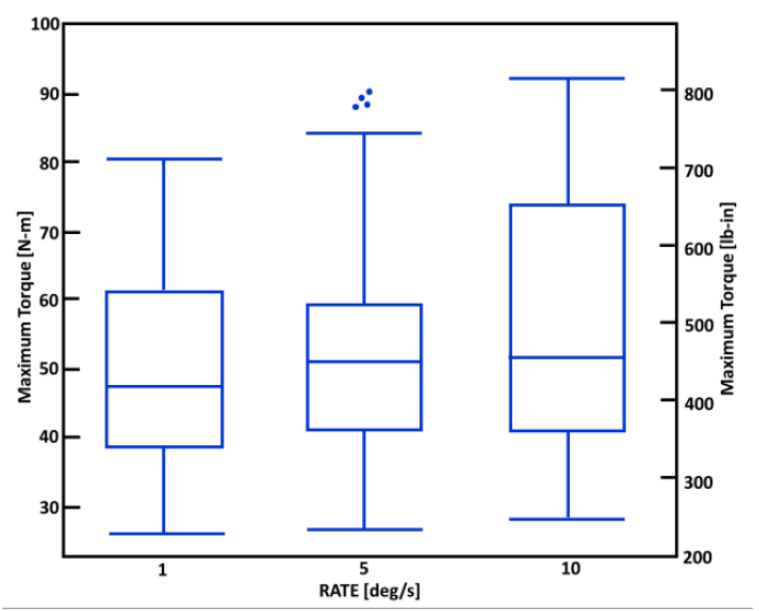

Fig. 5. Box-Whisker plot of the maximum torque for each all the data collected versus Rate of rotation

The more significant factors in this study are found to be the axial load applied during the test and the Spray condition.

\section{Discussion}

The ACL is more commonly injured from a noncontact situation than from player-to-player contact. Griffin et al. (2000) has shown that a cutting maneuver can result in an injury to the ACL. This study was designed to model a cutting maneuver on a hardwood court and determine if the use of traction enhancing products on the bottom of sneakers increases the likelihood of ACL injury.

Meyer et al. (2005) studied cadaveric knees tested in torsion to failure of the ACL. Their published torsional value of $37.4 \pm 16.8 \mathrm{~N}-\mathrm{m}(331 \pm 148.7 \mathrm{in}-\mathrm{lbs})$ resulted in failure of $100 \%$ of tested ACLs. All the data in Fig. 6 fall within the range identified by Meyer et al. (2005). The non-Spray data are consistently lower than the Spray data and none of the non-Spray data exceeds that maximum torque identified in the Meyer et al. (2005) study. This is in contrast to the Spray data where all the conditions exceed the maximum torque identified in the Meyer et al. (2005) study for causing an ACL injury.

In vivo, stresses developed during a cutting maneuver are dissipated through ligaments and in the viscoelastic deformation of tissues and are transferred away from the knee through soft tissue and bony structures. The testing model in this investigation is intentionally simplistic and does not take these effects into account. In order to isolate the effect of the Spray it was important to eliminate as many variables as possible. The study was designed to give a proportional representation of the increase torque that could be expected after application of an anti-slip product and this increased torque's potential increase risk of injury to the ACL. 


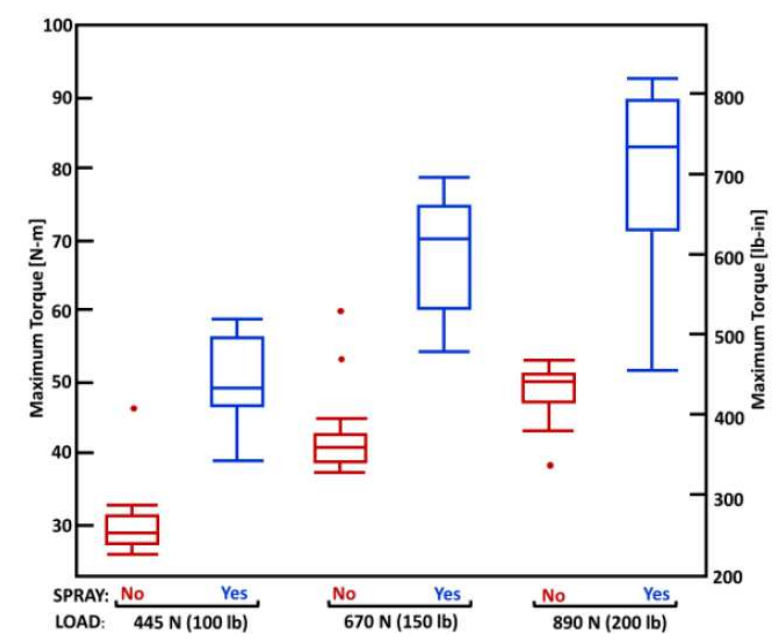

Fig. 6. Box-Whisker plot of the maximum torque for each all the data collected versus both the axial Load applied during the test and the Spray condition

Our study shows that proportionally more torsional load, which ultimately must be resisted by the ACL, is developed after an anti-slip product is applied.

A potential limitation to this study is that testing conditions are only an approximation of the true stresses occurring during a cutting maneuver. Although the experimental set-up fails to reproduce the complex forces that occur during an injury to the ACL, it is assumed that an increased amount of tension would be created in the ACL proportional to the increased torque between spray and no-spray conditions. The data from this study shows an approximate $164 \%$ increase in torque when spray is applied. For this reason, it is concluded that the ACL is at increased risk of injury when traction enhancing products are applied to shoes.

\section{Conclusion}

This study shows that, given adequate Load, there is sufficient friction between an untreated basketball shoe and a standard clean gymnasium floor to produce torque loads in excess of those shown to cause a cadaveric ACL to rupture. Furthermore, the application of anti-slip shoe products significantly increases this maximum torque even further. This investigation raises significant concern for the potential of an increased probability of ACL injury in those who use anti-slip shoe products.

\section{Acknowledgement}

We would like to thank Albany Medical College for donating the SACH type prosthetic foot for this study.

\section{Funding Information}

There were no significant financial contributions made to this study.

\section{Author's Contributions}

Morse, A: Contributed to the conception and design of the experiment. Contributed to drafting the manuscript and involved in the critical review process.

M.M. Mansfield: Contributed to the design of the experiment and acquisition, analysis and interpretation of the data. Contributed to drafting the manuscript and involved in the critical review process.

R.M. Alley: Contributed to the conception and design of the experiment. Contributed to drafting the manuscript and involved in the critical review process.

H.A. Kerr: Contributed to the conception and design of the experiment. Contributed to drafting the manuscript and involved in the critical review process.

R.B. Bucinell: Contributed to the design of the experiment and acquisition, analysis and interpretation of the data. Contributed to drafting the manuscript and involved in the critical review process.

\section{Ethics}

There are no ethical or financial conflicts of interest regarding the research presented in this study.

\section{References}

Box, G.E.P., J.S. Hunter and W.G. Hunter, 2005. Statistics for Experimenters. 2nd Edn., John Wiley and Sons, Hoboken, ISBN-10: 0-471-71813-0

CDCP, 2006. Injuries in Sports, Recreation and Exercise. Atlanta, GA.

Griffin, L.Y., J. Agel, M.J. Albohm, E.A. Arendt and R.W. Dick et al., 2000. Non-contact anterior cruciate ligament injuries: Risk factors and prevention strategies. J Am. Acad Orthop Surg., 8: 141-150. PMID: 10874221

Hewett, T.E., G.D. Myer, K.R. Ford, R.S. Heidt Jr. and A.J. Colosimo et al., 2005. Biomechanical measures of neuromuscular control and valgus loading of the knee predict anterior cruciate ligament injury risk in female athletes: A prospective study. Am. J. Sports Med., 33: 492-501. DOI: $10.1177 / 0363546504269591$

Hootman, J.M., C.A. Macera, B.E. Ainsworth, C.L. Addy and M. Martin et al., 2002. Epidemiology of musculoskeletal injuries among sedentary and physically active adults. Med. Sci. Sports Exerc., 34: 838-844. DOI: 10.1097/00005768-200205000-00017

Meyer, E.G. and R.C. Haut, 2005. Excessive compression of the human tibio- femoral joint causes ACL rupture. J. Biomech., 38: 2311-2316. DOI: 10.1016/j.jbiomech.2004.10.003

Racine, J., 2014. Aaron RK. Post-traumatic osteoarthritis after ACL injury. Rhode Island Med. J., 97: 25-28. 